\title{
FOOD CONSUMPTION PATTERNS OF SUB-SAHARAN AFRICAN IMMIGRANTS RESIDING IN GAUTENG PROVINCE, SOUTH AFRICA
}

\author{
Mbombo-Dweba, T. P. - Mbajiorgu, C. A. - Agyepong, A. O. - Oguttu, J. W. \\ Department of Agriculture and Animal Health, Science Campus, University of South Africa \\ Florida 1710, South Africa (e-mail: agyepao@unisa.ac.za, tel: + 27-1-14-712-264, fax: +27- \\ 11-4-712-260; joguttu@unisa.ac.za, tel:+27-1-14-713-353,fax : +27-1-14-712-260; \\ mbajica@unisa.ac.za, tel: +27-1-14-713-590,fax: +27-1-14-712-260) \\ *Corresponding author \\ e-mail:mbombtp@unisa.ac.za,tel: +27-1-14-712-264,fax:+27-1-14-712-260
}

(Received $15^{\text {th }}$ Mar 2017; accepted $31^{\text {st }}$ May 2017)

\begin{abstract}
Migration often leads to the loss of what is known as the "healthy immigrant effect" due to the adoption of unhealthy eating habits upon resettlement in host countries. A descriptive study was conducted to assess the current food practices of sub-Saharan immigrants residing in Gauteng Province, South Africa. Questionnaires were administered to 194 female participants residing in Gauteng. Data relating to socioeconomic factors, the adoption of South African food culture in general and specific food items that have been adopted were collected. The association between food adoption and socioeconomic factors was tested. Among the households polled, $78.4 \%$ had adopted South African food to varying degrees. Four adoption patterns emerged: strict continuity with traditional food; very limited adoption; limited adoption; and complete adoption of South African food culture. With regard to the association between food adoption and factors tested, the region of origin $(p<0.000)$ was highly significant, while money spent on food was marginally significant $(\mathrm{p}<0.077)$. Dietary acculturation was characterised by a high intake of energy-dense, high-fat and low-micronutrient foods. Culturally appropriate nutrition education studies are required. Future studies should assess the impact of these dietary patterns on health outcomes among immigrants living in South Africa.
\end{abstract}

Keywords: dietary acculturation, dietary patterns, food culture, food adoption patterns

\section{Introduction and background}

Recent immigration trends indicate that $70 \%$ of all international migration is interregional and takes place within the African continent (Adepoju, 2008). Consequently, ever since the apartheid dispensation ended in 1994, South Africa has seen an increase in the number of sub-Saharan immigrants due to unstable economic conditions, soaring ethnic conflicts, volatile political situations and drought situations in most African countries (Njomo, 2013; Statistics South Africa, 2014a). However, research has shown that immigrants undergo dietary acculturation upon settlement in new countries (Garnweidner et al., 2012; Njomo, 2013) due to unavailability and inaccessibility of their traditional ingredients in the host countries (Garnweidner et al., 2012; Deng et al., 2013). Dietary acculturation is defined as the process by which immigrant minority groups adopt the dietary habits of the host society (Deng et al., 2013).

Dietary acculturation often results in the adoption of unhealthy eating habits (Okafor et al., 2014; Terragni et al., 2014) and subsequent loss of what is known as the "healthy immigrant effect" (HIE) (Sanou et al., 2014). HIE is defined as a situation whereby immigrants are usually healthier than native-born population when they first arrive in host countries due to medical screening they are subjected to as part of the selection 
processes (Sanou et al., 2014). However, upon settlement in host countries, previous studies indicate (Lesser et al., 2014; Sanou et al., 2014) that immigrants loose the Healthy Immigrants Effect due to, among other factors dietary acculturation. Evidence suggests that African immigrants are at risk of weight gain and poor health outcomes owing to their poor food choices, when compared with immigrants from other continents (Venters and Gany, 2011; Okafor et al., 2014). According to Venters and Gany (2011), this could explain why the leading chronic diseases among African immigrants are hypertension and diabetes, which are lifestyle diseases.

It is reported that immigrants tend to increase their intake of ready-to-eat processed foods because they are unfamiliar with new foods and cooking items (Deng et al., 2013). According to a study that was conducted among Somali refugees in the United States of America (USA), the intake of snacks and sugary beverages increased significantly in this group of immigrants upon resettlement (Dharod et al., 2011). Replacing high-nutritive food with high-fat and calorie-dense food was also reported in a study that was conducted among Latin American immigrants residing in Toronto (Vahabi and Damba, 2013). Higher dietary acculturation characterised by increased consumption of fast foods and meat and a decrease in the consumption of fruits and vegetables was reported in a study that was conducted in the USA among African immigrants (Okafor et al., 2014). This places immigrants at a higher risk of developing lifestyle diseases - a situation which, if left unattended, could place an enormous burden on the health system of the host country. Sanou et al. (2014), in a review of acculturation studies conducted among immigrants living in Canada, argue that the burden of lifestyle diseases increases consistently after immigrants' settlement in host countries.

Although most studies on dietary acculturation have been conducted on immigrants moving from developing to developed countries, an increase in the intake of sweets, sweet baked goods and sweetened fruit drinks was reported in a study on Liberian immigrants residing in Ghana (Ross et al., 2016). This suggests that immigrants moving from one developing country to another are not immune to these unhealthy dietary changes when settling in developing host countries. Two past studies conducted in South Africa showed that sub-Saharan immigrants consume their indigenous foods at least three times a week (Njomo, 2012, 2013). The question, then, is what happens during the others days of the week? It is possible that some level of dietary acculturation is taking place among this group. Furthermore, what could be the possible implications of this dietary acculturation on the "Health Immigrant Effect"? However, there is no evidence of studies that have investigated dietary acculturation or factors that affect dietary acculturation among sub-Saharan immigrants living in South Africa.

The authors of this paper had three objectives: (1) to assess the dietary patterns of sub-Saharan immigrants residing in Gauteng; (2) to identify patterns of dietary acculturation among sub-Saharan immigrants upon resettlement; and (3) to identify factors that significantly affect the adoption of South African food.

\section{Methods}

\section{Research design}

A descriptive survey study design was adopted to obtain responses that would fulfil the objectives of this study. The study was conducted in Tshwane and Johannesburg 
because these two metropolitan municipalities together host the largest number of immigrants (Landau and Gindrey, 2008; Njomo, 2013).

\section{Study area}

South Africa does not have statistics on all immigrants currently residing in the country (Statistics South Africa, 2013). Therefore, information on the number of permits that were issued by the Department of Home Affairs in 2011 and 2013 was considered (Statistics South Africa, 2013, 2014a) when determining the regions to be included in this study. According to Statistics South Africa (2016), the majority of immigrants are from Southern Africa, followed by Central Africa and then East Africa. Therefore, for the purposes of this study, only immigrants from these regions were considered for this study.

\section{Development of questionnaire}

Literature from previous research informed the objectives of the study, which were used to develop the survey questionnaire. Gaps in the literature indicated the need to gain a greater understanding of the dietary patterns, acculturation and factors that affect dietary acculturation of sub-Saharan immigrants in South Africa. For the purposes of clarity, relevance, language and cultural appropriateness, the first draft of the questionnaire was reviewed independently by four sub-Saharan immigrant academics that have been residing in the country for over 15 years. Feedback was discussed by all authors to reach consensus before changes were effected.

The following changes were introduced, based on the recommendations of the reviewers: An option for self-employment was added; categories of income levels were created, rather than making this question open-ended; possible reasons for wanting to continue with the traditional food culture were added, from which respondents could choose; the wording of some questions was revised to make them more relevant to the target community (e.g. the term "food safety" was deemed to be unclear and was therefore changed to "quality of the food"); and owing to the diverse origin of immigrants, the question on the country of origin was changed to region of origin. The final draft questionnaire was then circulated to a group of 20 academics for final review.

The questionnaire was piloted on 34 female participants representing households from Southern, Central, East and West African regions. Two major changes were made, based on the results of the pilot study. Among the Southern African immigrants, the highest number of immigrants were from Zimbabwe, accounting for approximately $42.2 \%$ of the permits that were issued (Statistics South Africa, 2013, 2014b, 2016). During the pilot study, it was discovered that there was not much difference between South African and Zimbabwean food culture; therefore, the Southern African region was dropped from the main study. The question about the immigration status was also excluded, as most respondents were not comfortable answering that question. The final questionnaire had 4 sections aimed at capturing data on: socio-demographic and economic details of the respondents, adoption of the South African food, food items that have been adopted since settled in South Africa and 3-day food recall.

\section{Selection of participants}

The study targeted women, who are habitually responsible for food preparation in most households in African societies (Garnweidner et al., 2012; Njomo, 2013). In this 
study, owing to the lack of a sampling frame, it was not possible to adopt random sampling, which is known to yield representative samples. Furthermore, since relatively little is known about the phenomenon under investigation, snowball sampling was considered the most appropriate sampling technique for the study. Churches that host highest numbers of immigrants, businesses that employ immigrants, personal contacts of data collectors, referrals from academic staff members and networking were used to identify and recruit the first six participants of the study (two from each region). Each participant was then requested to identify two other immigrant households. This process was repeated until a statistically significant number of participants was reached. One hundred and ninety-four $(\mathrm{n}=194)$ female participants representing households from Central, East and West African regions were identified and invited to participate in the study.

\section{Data collection}

Four university students of sub-Saharan African descent were recruited and trained as data collectors. The data were collected between August 2015 and January 2016. A structured questionnaire consisting of both closed and open-ended questions was used to gather data on socio-demographic characteristics, dietary patterns and dietary acculturation. A three-day food recall was also used at the end of each questionnaire to triangulate the information gathered on the food items that have been adopted since the immigrants' arrival in South Africa. In cases where the responses were deemed insufficient or unclear, probing questions were used to elicit more information.

\section{Data analysis}

Quantitative data were coded and entered into a Microsoft Excel ${ }^{\circledR}$ worksheet. The data were then checked for any inconsistencies and missing values before analysis was performed using the statistical package IBM SPSS version 23 (2015). Data were summarised and descriptive statistics presented as graphs and tables. The probit model was used to identify associations between the adoption of South African food and sociodemographic and economic factors of the households. In this study, households that had adopted South African food culture were coded as 1, whereas those that had not adopted the South African food culture were denoted as 0.

Assumption of general probit model: $Y=\operatorname{Pr}(Y=1 \mid X)=\Phi\left(X^{\prime} \beta\right)$,

where Pr denotes probability; $\Phi$ is the cumulative distribution function (CDF) and $\beta$ is the parameters

The probit model, as a latent variable model with an auxiliary random variable, is expressed as: $\mathrm{Y}^{*}=\beta^{\prime} \mathrm{X}+\varepsilon$,

where $\varepsilon \sim N(0,1)$. Then $\mathrm{Y}$ can be viewed as an indicator of whether this latent variable is positive:

$$
Y=1_{\left\{y^{*}>0\right\}}=\left\{\begin{array}{l}
1 \text { if } Y^{*}>0 \text { i.e. }-\varepsilon<X^{\prime} \beta, \\
0 \text { otherwise }
\end{array}\right.
$$

Specific regression model: ASFC $=\beta_{0}+\beta_{1} \mathrm{~A}+\beta_{2} \mathrm{G}+\beta_{3} \mathrm{Edc}+\beta_{4} \mathrm{~B}+\beta 5 \mathrm{DR}+\beta_{6} \mathrm{P}+\beta_{7} \mathrm{MS}$ $+\beta_{8} \mathrm{R}+\beta_{9} \mathrm{ES}+\beta_{10} \mathrm{Y}+\beta_{11} \mathrm{MSF}$ 


\section{$\mathrm{Y}=\left\{\begin{array}{c}1 \text { if households have adopted South African food culture } \\ 0 \text { if households have not adopted South African food culture }\end{array}\right.$}

\begin{tabular}{|c|c|c|c|}
\hline Variable code & Name of variable & Variable description & $\begin{array}{l}\text { Unit of } \\
\text { measurement }\end{array}$ \\
\hline Dependent variable & \multirow[b]{2}{*}{$\begin{array}{l}\text { Adoption of South } \\
\text { African food culture }\end{array}$} & \multirow{2}{*}{$\begin{array}{l}1 \text { if households have adopted } \\
\text { South African food culture } \\
0 \text { if households have not adopted } \\
\text { South African food culture }\end{array}$} & \multirow[b]{2}{*}{ Dummy } \\
\hline $\mathrm{Y}=\mathrm{ASFC}$ & & & \\
\hline $\begin{array}{l}\text { Independent } \\
\text { variables }\end{array}$ & \multirow[b]{2}{*}{ Age } & \multirow{2}{*}{ Age of household member } & \multirow{2}{*}{ Number } \\
\hline $\mathrm{X}_{1}=\mathrm{A}$ & & & \\
\hline $\mathrm{X}_{3}=\mathrm{EdcL}$ & Education level & $\begin{array}{l}1 \text { if respondent has no formal } \\
\text { school education } \\
2 \text { if respondent has primary } \\
\text { education } \\
3 \text { if respondent has secondary } \\
\text { education } \\
4 \text { if respondent has tertiary } \\
\text { education }\end{array}$ & Dummy \\
\hline$X_{4}=D R$ & Duration of residence & $\begin{array}{l}1 \text { if respondent has resided here } \\
\text { for less than a year } \\
2 \text { if respondent has resided here } \\
\text { for } 1-3 \text { years } \\
3 \text { if respondent has resided here } \\
\text { for } 4-6 \text { years } \\
4 \text { if respondent has resided here } \\
\text { for more than } 7 \text { years. }\end{array}$ & Dummy \\
\hline $\mathrm{X}_{5}=\mathrm{MS}$ & Marital status & $\begin{array}{l}1 \text { if respondent is married } \\
2 \text { if respondent is unmarried } \\
3 \text { if respondent is divorced } \\
4 \text { if respondent is widowed }\end{array}$ & Dummy \\
\hline Variable code & Name of variable & Variable description & $\begin{array}{l}\text { Unit of } \\
\text { measurement }\end{array}$ \\
\hline $\mathrm{X}_{6}=\mathrm{R}$ & Region of origin & $\begin{array}{l}1 \text { if respondent is from West } \\
\text { Africa } \\
2 \text { if respondent is from East } \\
\text { Africa } \\
3 \text { if respondent is from Central } \\
\text { Africa }\end{array}$ & Dummy \\
\hline $\mathrm{X}_{7}=\mathrm{ES}$ & Employment status & $\begin{array}{l}1 \text { if respondent has a full-time job } \\
2 \text { If respondent has a part-time } \\
\text { job } \\
3 \text { If respondent has a temporary } \\
\text { assignment } \\
4 \text { if respondent is self- employed } \\
5 \text { if respondent is a student } \\
6 \text { if respondent is unemployed }\end{array}$ & Dummy \\
\hline $\mathrm{X}_{8}=\mathrm{Y}$ & Household income & $\begin{array}{l}0 \text { if there was no response } \\
1 \text { if respondent earns under } \\
\text { R5 } 000 \\
2 \text { if respondent earns between }\end{array}$ & Rand \\
\hline
\end{tabular}




\begin{tabular}{|c|c|c|c|}
\hline & & $\begin{array}{l}\mathrm{R} 5000 \text { and } \mathrm{R} 10000 \\
3 \text { if respondent earns between } \\
\mathrm{R} 11000 \text { and } \mathrm{R} 15000 \\
4 \text { if respondent earns between } \\
\mathrm{R} 16000 \text { and } \mathrm{R} 20000 \\
5 \text { if respondent earns between } \\
\mathrm{R} 21000 \text { and } \mathrm{R} 25000 \\
6 \text { if respondent earns between } \\
\mathrm{R} 26000 \text { and } \mathrm{R} 30000 \\
7 \text { if respondent earns more than } \\
\mathrm{R} 30000\end{array}$ & \\
\hline $\mathrm{X}_{9}=\mathrm{MSF}$ & Money spent on food & $\begin{array}{l}1 \text { if respondent spends under } \\
\text { R500 } \\
2 \text { if respondent spends between } \\
\text { R500 and R1 } 499 \\
3 \text { if respondent spends between } \\
R 1500 \text { and R2 } 499 \\
4 \text { if respondent spends between } \\
R 2500 \text { and R3 } 499 \\
5 \text { if respondent spends between } \\
R 3500 \text { and R4 } 500\end{array}$ & Dummy \\
\hline
\end{tabular}

\section{Ethical considerations}

Ethical clearance (2014/CAES/113) for the study was obtained from the College of Agriculture and Environmental Science, University of South Africa before the study could commence. After study objectives were explained to the participants, only those who granted informed consent participated in the study.

\section{Results}

\section{Socioeconomic results}

As shown in Table 1, the majority of the respondents $(79 \% ; n=153)$ were aged between 20 and 39 years. Most respondents $(53.6 \%$; $=104)$ were single and $56.7 \%$ $(n=110)$ had tertiary education, while $43.3 \%$ had only a high school education or lower. More than half $(62.9 \%$; $n=122)$ of the respondents had lived in South Africa for more than four years. Most respondents $(41 \% ; n=80)$ were from West Africa, while $30 \%$ $(n=58)$ were from Central Africa and 29\% $(n=56)$ were from East Africa.

Table 1. The socio-demographic details of respondents showing their age, education, marital status and duration of residence in South Africa and region of origin

\begin{tabular}{l|c|c}
\hline Variable & $\begin{array}{c}\text { Number of respondents } \\
(\mathbf{n = 1 9 4 )}\end{array}$ & Percentage (\%) \\
\hline Age & & \\
Below 20 & 7 & 3.6 \\
$20-29$ & 89 & 46 \\
$30-39$ & 64 & 33 \\
$40-49$ & 24 & 12.4 \\
$50-59$ & 8 & 4.0 \\
\hline
\end{tabular}




\begin{tabular}{l|c|c}
\hline $60-69$ & 1 & 0.5 \\
Over 70 years & 1 & 0.5 \\
Educational level & & \\
No formal education & 6 & 3.1 \\
Less than high school education & 78 & 40.2 \\
Tertiary education & 110 & 56.7 \\
Marital status & & \\
Single & 104 & 53.6 \\
Married & 81 & 41.7 \\
Divorced/widowed & 9 & 4.6 \\
Duration of residence in South & & \\
Africa & 10 & 5.1 \\
Less than a year & 62 & 32.0 \\
1-3 years & 60 & 30.9 \\
$4-6$ years & 62 & 32.0 \\
7 years or more & & \\
Region of origin & 80 & 41 \\
West Africa & 56 & 29 \\
East Africa & 58 & 30 \\
Central Africa & & \\
& & \\
\hline
\end{tabular}

Table 2 describes employment status, household income and money spent on food, as reported by the households included in the study. Monthly household income of the respondents ranged from R500 to R30 000, with 32.0\% ( $n=62)$ earning under R5 000 and only $16.5 \%(n=32)$ earning above R20 000.

Table 2. Economic details of the respondents

\begin{tabular}{l|c|c}
\hline Variable & $\begin{array}{c}\text { Number of respondents } \\
(\mathbf{n = 1 9 4})\end{array}$ & Percentage (\%) \\
\hline Employment status & & \\
Full-time job & 61 & 31.4 \\
Part-time job & 18 & 9.3 \\
Temporary job & 3 & 1.5 \\
Self-employed & 80 & 41.2 \\
Student & 13 & 6.7 \\
Unemployed & 18 & 9.2 \\
Household income per month & & \\
No response & 3 & 1.5 \\
Under R5 000 & 62 & 32.0 \\
R5 000-R10 000 & 56 & 28.9 \\
\hline
\end{tabular}




\begin{tabular}{l|c|c}
\hline R11 000-R15 000 & 27 & 13.9 \\
R16 000-R20 000 & 14 & 7.2 \\
R21 000-R25 000 & 5 & 2.6 \\
R26 000-R30 000 & 12 & 6.2 \\
Above R30 000 & 15 & 7.7 \\
Money spent on food per month & & \\
Under R500 & 15 & 7.7 \\
R500-R1 499 & 65 & 33.5 \\
R1 500-R2 499 & 43 & 22.1 \\
R2 500-R3 499 & 45 & 23.1 \\
R3 500-R4 500 & 26 & 13.4 \\
\hline
\end{tabular}

\section{Adoption of the South African food culture}

Out of 194 respondents, $78.4 \%(n=152)$ indicated that they had adopted the South African food culture (Table 3). Among those who had adopted South African foods, the level of adoption varied considerably. Based on the findings of this study, the following four (4) patterns of dietary acculturation emerged: strict continuity with their traditional food $(21.6 \% ; \mathrm{n}=42)$; very limited adoption $(21.1 \% ; \mathrm{n}=39)$; limited adoption $(50.5 \%$; $\mathrm{n}=98)$; and complete adoption of South African food culture $(7.7 \% ; n=15)$. Complete adoption of South African food was explained as eating South African food during all mealtimes and eating traditional food only on special occasions, such as at cultural gatherings, weddings and naming ceremonies. Limited adoption meant eating South African food in combination with traditional food; very limited adoption was used to describe eating traditional food at all mealtimes, while eating South African foods only when visiting friends or dining out. Strict continuity with traditional food meant that the respondents always eat traditional food for all meals.

Table 3. Adoption of South African food

\begin{tabular}{l|c|c}
\hline Variable & $\begin{array}{c}\text { Number of respondents } \\
(\mathbf{n = 1 9 4})\end{array}$ & Percentage (\%) \\
\hline Adoption of South African food & & 78.4 \\
Yes & 152 & 21.6 \\
No & 42 & \\
Level of adoption & & 21.6 \\
Strict continuity with traditional & 42 & 50.5 \\
food & 98 & 20.1 \\
Limited adoption & 39 & 7.7 \\
Very limited adoption & 15 & \\
Strictly SA food & & 21.6 \\
Reasons for adopting & 42 & \\
Not applicable & & \\
\hline
\end{tabular}




\begin{tabular}{l|c|c}
\hline Traditional food too expensive & 76 & 39.2 \\
Unavailability of traditional food & 49 & 25.3 \\
Convenience & 15 & 7.7 \\
I like South African food & 8 & 4.1 \\
My kids prefer it & 4 & 2.1 \\
Reasons for not adopting & & \\
Not applicable & 152 & 78.4 \\
Unfamiliar taste & 33 & 17.0 \\
Inability to cook SA food & 6 & 3.1 \\
SA food is unhealthy & 3 & 1.5 \\
\hline
\end{tabular}

During the interviews, it became clear that immigrants did not distinguish food that was part of the South African cuisine from globalised or westernised foods. They considered all food - including fast food - to be part of the traditional South African food culture, as long as it fell outside their original food culture.

Respondents gave various reasons for adopting South African food (see Table 3). Among the households that reported adopting the South African food culture, the most common reason was that the price of traditional food was too high $(50 \% ; n=76)$, followed by the unavailability of the traditional food $(32.2 \%$; $=49)$.

Of the 42 respondents that have not adopted South African food, the main reason given was the unfamiliar taste $(79 \% ; n=33)$. Other reasons included inability to cook South African food $(14.2 \% ; n=6)$ and the fact that other immigrants believed the food is unhealthy $(7 \% ; n=3)$.

\section{Food items that have been adopted since resettlement}

An assessment of the food items that the respondents had started eating after settling in South Africa revealed the following to be the most common: pap (84.5\%; $n=164)$; fried potato chips $(43.8 \% ; n=85)$; cold drinks $(42.8 \% ; n=83)$, fast foods $(37.6 \% ; n=73)$; sphathlo $(30.9 \% ; \mathrm{n}=60)$; vetkoek (fat cakes) $(30.4 \% ; \mathrm{n}=59)$; and spinach $(24.2 \% ; \mathrm{n}=47)$. Pap is a typical South African staple food made from maize meal, while sphathlo (sometimes known as kota) is an African burger made of a quarter loaf of bread and usually filled with at least five ingredients, including potato chips, cheese, polony, Russians (spicy sausages), atchar (a spicy condiment), fried eggs and tomato sauce. Other items that are sometimes also included in sphathlo are chakalaka (a spicy vegetable relish), braai meat, samp (coarsely ground mealie meal) and beans. Sphathlo is commonly consumed in the townships of Gauteng. 


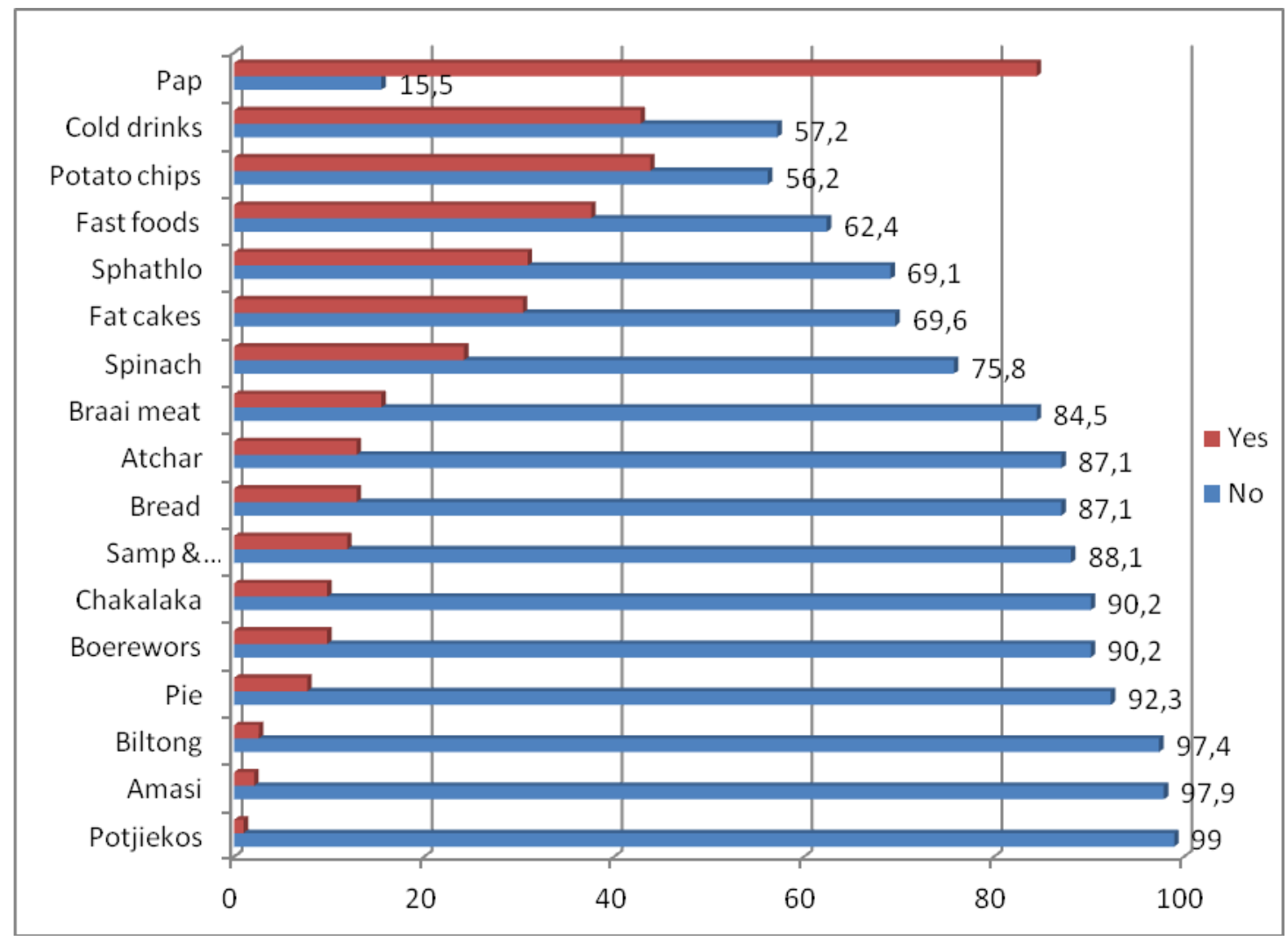

Figure 1. South African food adoption showing different food items that have been adopted by immigrants since their re-settlement in South Africa

Consumption of fizzy drinks was also common among immigrants, with most respondents consuming at least one fizzy drink every day. The leading fast food outlets mentioned by respondents were Kentucky Fried Chicken, MacDonald's, Steers, Nando's and Roman's Pizza.

\section{Factors associated with the adoption of South African food}

At 0.05 cut off significance level, the region of origin was highly significant $(p<0.000)$, while money spent on food was marginally significant $(p<0.077)$. No statistically significant associations were observed for the rest of the factors that were tested.

Table 4. Factors associated with the adoption of south african food

\begin{tabular}{l|l|r|r|r|r|r|r}
\hline \multicolumn{7}{c}{ Parameter estimates } \\
\hline & & & & & & \multicolumn{2}{c}{$95 \%$ confidence interval } \\
\hline \multirow{2}{*}{ PROBIT $^{\mathrm{a}}$} & Parameter & Estimate & \multicolumn{1}{c}{$\begin{array}{c}\text { Std. } \\
\text { error }\end{array}$} & \multicolumn{1}{c}{$\mathrm{Z}$} & \multicolumn{1}{c}{ Sig. } & $\begin{array}{c}\text { Lower } \\
\text { bound }\end{array}$ & $\begin{array}{c}\text { Upper } \\
\text { bound }\end{array}$ \\
& Region & -.264 & .038 & -6.920 & .000 & -.338 & -.189 \\
& Marital status & -.057 & .043 & -1.338 & .181 & -.142 & .027 \\
& Age & -.013 & .033 & -.386 & .700 & -.077 & .052 \\
& Qualification & .007 & .025 & .289 & .773 & -.042 & .056
\end{tabular}




\begin{tabular}{l|r|r|r|r|r|r}
\hline & $\begin{array}{l}\text { Employment } \\
\text { status }\end{array}$ & -.011 & .019 & -.551 & .582 & -.049 \\
$\begin{array}{l}\text { Household } \\
\text { income }\end{array}$ & .008 & .018 & .433 & .665 & -.027 & .027 \\
$\begin{array}{l}\text { Money spent } \\
\text { on food }\end{array}$ & -.027 & .015 & -1.770 & .077 & -.057 & .003 \\
$\begin{array}{l}\text { Duration of } \\
\text { residence }\end{array}$ & -.013 & .034 & -.378 & .705 & -.079 & .053 \\
Intercept & -1.571 & .245 & -6.416 & .000 & -1.815 & -1.326 \\
\hline
\end{tabular}

a. PROBIT model: $\operatorname{PROBIT}(\mathrm{p})=$ Intercept + BX

\section{Discussion}

Results on the age of the respondents confirm findings that the majority of the immigrants are young (Vahabi and Damba, 2013; Anderson et al., 2014) and have probably moved in search of better economic conditions. While most immigrants participating in our study were fairly educated $(56.7 \%$; $=110)$, the low-income categories (i.e. below ZAR15 000 per month) into which the majority of respondents (74.8\%; $\mathrm{n}=145)$ fell suggest that our study population falls into the low-income bracket. This income is below the South African average monthly income of ZAR17 517(Statistics South Africa, 2016). Low incomes and the fact that only $31.4 \%$ of immigrants are in full-time jobs suggest that they are finding it difficult to secure decent jobs. The prevalence of low socioeconomic status among the respondents in this study was consistent with the results of similar studies of sub-Saharan immigrants that have resettled in other countries (Vahabi and Damba, 2013; Anderson et al., 2014; Ross et al., 2016). As a result, their dietary acculturation is likely to be characterised by negative dietary changes (Kiptinness et al., 2011). Difficulty in finding employment among well-educated immigrants was associated with language barriers (Vahabi and Damba, 2013) and employment restrictions imposed on foreign nationals (Shackelford, 2010). In the current study, the low employment level could be aggravated by the high unemployment rate in South Africa, which is currently at 26.6\% (Statistics South Africa, 2016).

Consistent with previous studies, the current study revealed that even though the majority of immigrants try to preserve their traditional food culture upon resettlement, some level of dietary acculturation takes place (Garnweidner et al., 2012; Njomo, 2013; Sanou et al., 2014). For example, in a Norwegian study on African and Asian immigrants conducted by Garnweidner et al. (2012), different patterns of dietary acculturation were observed. Therefore, the authors of the current study are of the view that dietary acculturation does not move in a linear process. This view is supported by Deng et al. (2013), who contends that Chinese immigrants residing in North America do not just change their diets from traditional to strictly new foods upon resettlement. Instead, immigrants retain traditional foods, find new ways of incorporating their traditional ingredients and exclude others, while adopting new ones (Satia, 2010).

While Garnweidner et al. (2012) identified three patterns of dietary acculturation, the authors of the current study observed four patterns. However, in the same study by Garnweidner et al. (2012), none of the participants had completely adopted the host country's food culture. 
In the case of South Africa, the fact that immigrants are able to continue with their traditional or ethnic diets could be attributed to traditional foods' being available and sold by small ethnic shops (Njomo, 2012). However, these ethnic shops are reportedly very expensive when compared with the mainstream supermarkets (Njomo, 2012; Dharod et al., 2013). This situation could lead to food inaccessibility and hence accelerated dietary acculturation.

As was observed in previous studies (Garnweidner et al., 2012; Deng et al., 2013), high prices and unavailability of traditional food were the main reasons given by respondents for adopting South African foods. In view of this, adopting the South African food culture suggests that dietary change is not voluntary and might happen haphazardly before immigrants get a chance to familiarise themselves with the local food culture. This has important policy implications because of evidence suggesting that most immigrants often replace pricey, nutrient-rich foods with cheaper, energy-dense but low-micronutrient foods (Anderson et al., 2014). According Deng et al. (2013), when dietary acculturation occurs, breakfast is the first meal to be replaced by food items such as oatmeal, milk, bagels and cream cheese, a transition that predisposes the consumers to obesity and type 2 diabetes. Although there are dietary guidelines for the general South African population (Vorster et al., 2013), there is no record of nutrition education programmes that target immigrants in South Africa. The authors are therefore of the view that welfare resettlement and nutrition education programmes are required to help minimise the negative impact of acculturation among immigrants settling in the country.

Studies show that taste is associated with resistance to adopting the new food culture (Garnweidner et al., 2012; Dharod et al., 2013; Vahabi and Damba, 2013). This is consistent with the findings of this study, which showed that unfamiliar taste contributed to some immigrants' not adopting South Africa's food culture. A similar observation was made by Vahambi and Damba (2013) in a study they conducted in Toronto among Latin American immigrants. There, too, they concluded that difference in the taste of food resulted in a rejection of the new food culture.

In examining the changes in food habits, the results of our study indicated that the intake of energy-dense, highly processed food among immigrants had increased significantly after they had settled in South Africa. These findings are consistent with the findings of previous studies (Deng et al., 2013; Lesser et al., 2014; Okafor et al., 2014). Okafor et al. (2014) also reported that dietary changes among African immigrants in the United States were characterised by foods high in fat, sugar and cholesterol. An increase in the intake of convenience foods, fizzy drinks, desserts, candy and dining out among Asian immigrants residing in Canada was also reported by Lesser et al. (2014). Deng et al. (2013) argue that as Chinese immigrants settle in the United States, their diets tend to become more westernised. These dietary behaviours are highly discouraged as they are associated with lifestyle diseases such as obesity and type 2 diabetes (Deng et al., 2013; Okafor et al., 2014).

The unhealthy food choices observed among immigrants have been attributed to their low socioeconomic status. This is because these poor-quality food items are usually less costly than more nutritious food (Dharod et al., 2011; Okafor et al., 2014). In addition, Okafor et al. (2014) suggest that since most immigrants live below the poverty line in their new home countries, they are usually forced to work multiple low-paying jobs, thus reducing food accessibility and time to prepare traditional food dishes. In view of the fact that the current study also indicated that the majority of the immigrants $(76.3 \%)$ 
live below the average monthly gross income of ZAR17 517(Statistics South Africa, 2016), they are likely to experience difficulty in accessing nutritious food, which tends to be more costly. Apart from economic constraints, the increase in the consumption of unhealthy fast foods could also be due to a lack of knowledge on how to prepare new food items. Meanwhile, unhealthy nutrition transitions have also been associated with lifestyle factors, such as urbanisation and globalisation, which result in the high accessibility of fast foods and fizzy drinks (Satia, 2010). Furthermore, it is reported that prior to immigration, most immigrants are accustomed to small shops, open markets and fresh foods (Njomo, 2012; Terragni et al., 2014); therefore, moving to a place like Johannesburg or Pretoria - where there are many large supermarkets - could curtail their shopping capabilities. This could explain why immigrants resort to fast, cheap, energy-dense foods.

It is not always the case that immigrants respond negatively when faced with the challenges of adopting new food cultures. Some authors have found that immigrants sometimes make positive dietary changes (Lesser et al., 2014; Sanou et al., 2014). The question, then, is what causes these immigrants to make positive changes, while others do not? Is it a lack of knowledge of nutrition and unfamiliarity with the cooking methods and new foods that prevent immigrants from making healthy food choices? Available evidence suggests that positive dietary changes are associated with nutrition education initiatives (Lesser et al., 2014).

Consistent with the observation by Okafor et al. (2014), the region of origin in the current study was highly significant $(P=.000)$ at the confidence level of 5\%. Okafor et al. (2014) observed in their study that immigrants from Ethiopia and Nigeria were more acculturated than immigrants from other sub-Saharan countries. Moreover, Okafor et al. (2014) observed that the diets of the more acculturated immigrants were characterised by an increased consumption of fast foods and a decreased consumption of fruits and vegetables.

The other factor that was marginally associated with the adoption of South African foods was the money spent on food. This was expected, given that the majority of immigrants $(76.3 \%)$ who participated in this study indicated that they lived on less than the average national monthly gross income of South Africa, namely ZAR17 517(Statistics South Africa, 2016).

In previous studies, factors such as age, education level, income (Deng et al., 2013; Okafor et al., 2014) and the duration of residence (Dharod et al., 2011; Okafor et al., 2014) had a significant influence on food adoption, whereas in the current study these factors did not prove to be significantly associated with the adoption of South Africa food culture. The fact that there are differences between the current study and the studies reported on above in terms of geographical location of the studies and methodologies adopted could explain the differences in the findings.

In the literature, length of residence has been associated with dietary acculturation (Deng et al., 2013; Lesser et al., 2014). For example, Deng et al. (2013), observed that a longer duration of stay by Korean immigrants in the USA resulted in higher acculturation among younger immigrants (Deng et al., 2013). In contrast, length of residence was not associated with dietary acculturation in the current study. However, the findings of the current study are in agreement with what Ross et al. (2016) reported with regard to factors associated with dietary patterns, namely that duration of stay was not associated with the adoption of the host country's food culture among Liberian immigrants living in Ghana. In fact, these same authors observed that dietary patterns 
among Liberian immigrants remained different from those of the local population, irrespective of the number of years they had stayed in Ghana. The explanation for these contradictions could be attributed to the fact that these other studies (e.g. Deng et al., 2013; Lesser et al., 2014) were conducted on other continents, where circumstances are different.

In their study, Lesser et al. (2014) observed a different scenario from what our study and other studies have observed. Lesser et al. (2014) observed that a longer stay was associated with both negative and positive dietary changes. Positive changes included improved cooking methods, while negative dietary changes included increased consumption of red meat, fizzy drinks and desserts (Deng et al., 2013).

\section{Limitations of the current study}

The current study has a number of limitations. The use of non-probability sampling to select respondents for this study and the location where the study was conducted preclude any generalisation of the results. Therefore, the results reported here remain valid for the respondents involved and may be indicative of the problems experienced by sub-Saharan immigrants residing in South Africa. Consequently, validating these results in a different context and using a different sampling method would be valuable for further research. Another limitation of this study is that it did not measure food insecurity. Research has shown that there is high prevalence of food insecurity among immigrant groups, especially recent immigrants (Vahabi and Damba, 2013; Anderson et al., 2014). Thirdly, immigrants in this study were not grouped according to their immigration status. Research has shown that refugees and recent immigrants are highly vulnerable to food insecurity (Dharod et al., 2013). Lastly, the three-day food recall used in this study did not collect information on portion sizes, nor did it collect information on cooking methods and the ingredients used, especially for the traditional immigrant foods.

\section{Conclusion and recommendations}

To the best of our knowledge, the current study is the first of its kind to investigate dietary changes of immigrants in South Africa. An important finding of this study is that traditional food features very prominently in the dietary patterns of sub-Saharan immigrants. However, owing to high prices and unavailability of traditional ingredients, involuntary dietary acculturation takes place, forcing immigrants into bicultural eating patterns. High prices and unavailability of traditional ingredients could also make immigrants vulnerable to food insecurity. Therefore, further studies to identify similartasting, nutritious food items from the South African food culture - as substitutes for unavailable traditional ingredients - might be useful in preventing food rejection and informing culture-specific nutrition education programmes, which could contribute to positive nutritional transitions. Furthermore, our findings confirm that when dietary acculturation occurs, immigrant populations tend to adopt less healthy dietary patterns. In the long run, these unhealthy eating patterns could have negative implications, not only for the health of the immigrants themselves, but also for the health system in South Africa. This suggests the need to design targeted food security and culture-appropriate nutrition education programmes. Further studies to improve understanding of the severity and implications of unhealthy eating patterns among sub-Saharan immigrants in South Africa could help to inform policy and programmes aimed at improving the resettlement of immigrants. 
Finally, the findings of this study suggest that there is no association between marital status, age, household income, duration of residence and the adoption of the South African food culture.

\section{REFERENCES}

[1] Adepoju, A. (2008): Current African Issues - Migration in sub-Saharan Africa. - The Nordic Africa Institute.

[2] Anderson, L., Hadzibegovic, D. S., Moseley, J. M., Sellen, D. W. (2014): Household food insecurity shows associations with food intake, social support utilization and dietary change among refugee adult caregivers resettled in the United States. - Ecology of food and nutrition 53 (3):312-32.

[3] Deng, F., Zhang, A., Chan, C. (2013): Acculturation, dietary acceptability, and diabetes management among Chinese in North America. - Frontiers in endocrinology 4(108):1-7.

[4] Dharod, J. M., Croom, J., Sady, C. G., Morrell, D. (2011): Dietary intake, food security, and acculturation among Somali refugees in the United States: results of a pilot study. Journal of Immigrant and Refugee Studies (9):82-97.

[5] Dharod, J. M., Xin, H., Morrison, S. D., Young, A., Nsonwu, M. (2013): Lifestyle and Food-Related Challenges Refugee Groups Face Upon Resettlement: Do we Have to Move Beyond Job and Language Training Programs? - Journal of Hunger and Environmental Nutrition 8 (2):187-199.

[6] Garnweidner, L. M., Terragni, L., Pettersen, K. S., Mosdøl, A. (2012): Perceptions of the host country's food culture among female immigrants from Africa and Asia: aspects relevant for cultural sensitivity in nutrition communication. - Journal of nutrition education and behavior. 44 (4):335-42.

[7] Kiptinness, C., Dharod, J. M. (2011): Bhutanese Refugees in the United States: Their Dietary Habits and Food Shopping Practices Upon Resettlement. - Journal of Hunger and Environmental Nutrition 6 (1):75-85.

[8] Landau, L. B., Gindrey, V. (2008): Migration and Population Trends in Gauteng Province 1996-2055. (42). Johannesburg.

[9] Lesser, I., Gasevic, D., Lear, S. (2014): The Association between Acculturation and Dietary Patterns of South Asian Immigrants. - Plos One. 9 (2):1-6.

[10] Njomo, L. M. (2012): Satisfying the indigenous food needs of sub-Saharan African immigrants in South Africa: A food consumption behaviour model for South Africa's leading supermarket chains. - African Journal of Business Management 6 (25):75577568 .

[11] Njomo, L. M. (2013): Examining the impacts of ethnic grocery shops on the food consumption behaviour of sub-Saharan African immigrants in South Africa. - Universal Journal of Education and General Studies 2 (4):142-149.

[12] Okafor, M., Carter-Pokras, O.,Zhan, M. (2014): Greater Dietary Acculturation (Dietary Change) Is Associated With Poorer Current Self-Rated Health Among African Immigrant Adults. - Journal of nutrition education and behavior 46 (4):226-235.

[13] Ross, W. L., Gallego, D. F., Pérez, R., Amber, E., Fiedler, H., Lartey, A., Sandow, A. (2016): Dietary patterns in Liberian refugees in Buduburam , Ghana. - Martenal and Child Nutrition (June):1-10.

[14] Sanou, D., O’Reilly, E., Ngnie-Teta, I., Batal, M., Mondain, N., Andrew, C., Newbold, B. K., Bourgeault, I. L. (2014): Acculturation and nutritional health of immigrants in Canada: a scoping review. - Journal of immigrant and minority health / Center for Minority Public Health. 16 (1):24-34.

[15] Satia, J. (2010): Dietary acculturation and the nutrition transition: an overview. - This is one of a selection of papers published in the CSCN-CSNS 2009 Conference, entitled Can we. Applied physiology, nutrition, and metabolism. 
[16] Shackelford, E. (2010): Issue Brief : Immigration and Socioeconomic Status. 1-7.

[17] Statistics South Africa. (2013): Discussion document Documented immigrants in South Africa 2011. Pretoria.

[18] Statistics South Africa (2014a): Documented immigrants in South Africa , 2013. Pretoria.

[19] Statistics South Africa. (2014b): General Household Survey 2013.- Statistical release P0318. Pretoria.

[20] Statistics South Africa. (2016): Media Release: Quartely Employment Statistics, December 2015. Pretoria.

[21] Terragni, L., Garnweidner, L. M., Pettersen, K. S., Mosdøl, A. (2014): Migration as a turning point in food habits: the early phase of dietary acculturation among women from South Asian, African, and Middle Eastern Countries living in Norway. - Ecology of food and nutrition 53 (3):273-91.

[22] Vahabi, M., Damba, C. (2013): Perceived barriers in accessing food among recent Latin American immigrants in Toronto. - International journal for equity in health 12(1):1.

[23] Venters, H., Gany, F. (2011): African immigrant health. - Journal of Immigrant and Minority Health 13 (2):333-344.

[24] Vorster, H. H., Badham, J. B., Venter, C. S. (2013): Food-Based Dietary Guidelines for South Africa. - South African Journal of Clinical Nutrition 26 (3):5-12. 